\title{
IMPLEMENTATION OF SPACE VECTOR PULSE WIDTH MODULATION TECHNIQUE WITH GENETIC ALGORITHM TO OPTIMIZE UNIFIED POWER QUALITY CONDITIONER
}

\author{
M. Shankar, S. Monisha, H. Shesna, T. Vignesh, \\ N. Sikkandar, S. Sundaramoorthi and S. Venkatesh \\ Department of Electrical and Electronics Engineering, \\ Sasurie College of Engineering, Vijayamangalam, India
}

Received 2013-01-10; Revised 2013-04-12; Accepted 2013-12-14

\begin{abstract}
This study proposes a novel control design of Unified Power Quality Conditioner (UPQC). This design is enabled by a control framework that employs Genetic Algorithm which determines optimum points and angle for filtering and Space Vector Pulse Width Modulation Technique (SVPWM) to offer significant flexibility to optimize waveform. In addition the same framework integrates the major functions of the UPQC with ease to unify the treatments of several power quality problems including system harmonics in the supply voltage and load current, sags/swells in the supply voltage, variations in the load demands and poor power factor at the supply side. Simulation studies on a three phase power distribution system are used to verify the performance and implementation of this control design with the UPQC.
\end{abstract}

Keywords: Harmonics Compensation, Genetic Algorithm (GA), Space Vector Pulse Width Modulation Technique (SVPWM), Power Quality, Unified Power Quality Conditioner (UPQC)

\section{INTRODUCTION}

Nowadays, the increasing use of nonlinear power electronics loads in industries has led to harmonics generation. This poses great concerns for both the utilities and customers. Voltage sags/swells in the supply voltage and poor power factor at the supply side also add to the number of power quality problems that the customers face. As such, compliance with power quality standard is pursued through the installation of compensating devices. UPQC is used to compensate for current harmonics produced by nonlinear loads, but also to eliminate voltage flicker/imbalance appearing at the receiving terminal from the load terminal (Fujita and Akagi, 1998).

Some of the devices that are able to resolve these power quality problems include dynamic voltage restorers (Barros and Silva, 2010), uninterruptible power supplies (Kim and Lee, 2010), active power filters (Rahmani and Al-Haddad, 2012) and Unified Power Quality Conditioners (UPQCs). The UPQC is made up of the series and shunt active filters Varma and Neelima, 2012). It can be deployed in micro grids as well as in manufacturing plants like petrochemical plants and semiconductor plants that are dependent on a stable supply voltage.

The multivariable regulator theory with $\mathrm{H}_{\text {infin }}$ loop shaping, so that zero steady-state error, robustness to modeling uncertainties and insensitivity to supply frequency variations can be accomplished simultaneously, thus providing a complete theoretical solution to all the aforementioned PQ problems (Kwan and So, 2009). The design is made-up using classic control methods, all of them in the discrete-time-frequency domain and several tests in the laboratory prototype illustrate the overall dynamic and static performance of the system (Munoz et al., 2012). The modeling of the shunt Active Power Filter (APF) with close-loop control, a feed forward Corresponding Author: M. Shankar, Department of Electrical and Electronics Engineering, Sasurie College of Engineering, Vijayamangalam, India 
compensation path of load current is proposed to improve the dynamic performance of the APF (Chen and Chen, 2012). The neutral current that may flow toward transformer neutral point is compensated by using a four-leg voltage source inverter topology for shunt part. Thus, the series transformer neutral will be at virtual zero potential during all operating conditions (Khadkikar and Chandra, 2009).

Recently significant attention has been paid to the control circuit designs of the UPQC, with the objective to obtain reliable control algorithms and fast response procedures so that the UPQC can simultaneously tackle most of the power quality problems in a power distribution system and can collectively replace some of the power quality devices to reduce space and resources. While ensuring robustness and efficiency, the deployment of the UPQC has to be cost effective to remain competitive. As such, modern control theories are used in the control design for the UPQC. In view of the above issues this study presents an algorithm based on Genetic which determines optimum points and angle for filtering and Space Vector Pulse Width Modulation Technique (SVPWM) (Massoud and Williams, 2010) to offer significant flexibility to optimize waveform.

\subsection{Modeling of the Plant}

The schematic diagram of a Unified Power Quality Conditioner (UPQC) compensated distribution system is shown in Fig. 1. This is useful when both source and load are unbalanced and distorted. A UPQC combines a series and a shunt compensator together (Varma and Neelima, 2012).

It can therefore yield the benefits of both these devices. For example it can tightly regulate the load bus voltage. Therefore all loads including the unbalanced and nonlinear load will have a supply voltage that is balanced and sinusoidal. The UPQC can also make the current drawn from the supply (Is) balanced, sinusoidal and in phase with the terminal voltage. Therefore the voltage of any bus upstream from the PCC will not be affected due to a nonlinear and unbalanced load.

The UPQC shown in Fig. 2 consists of two VSCs (VSC1 and VSC2) that are connected back to back through a common dc capacitor. Series converter (VSC1) is connected through transformers between the supply and Point of Common Coupling (PCC). Shunt Converter (VSC2) is connected in parallel with PCC through the transformers (Kolhatkar and Das, 2007). VSC1 operates as a voltage source while VSC2 operates as a current source. The power circuit of VSC1 consists of three single-phase H-bridge voltage-source PWM inverters. Hbridge inverters are controlled independently.
The main objective of VSC1 is to mitigate voltage sags/swells (Kumar and Mishra, 2011) originating from supply side. The ac filter inductor and capacitor are connected in each phase to prevent the flow of harmonic currents generated due to switching. The transformers connected at the output of each H-bridge inverter provide isolation, modify voltage/current levels and prevent the dc capacitor from being shorted due to the operation of various switches. VSC2 is directly connected through a boost inductor which can boost up the common dc link voltage to the desired value.

\subsection{Control Methods}

Next, this section discusses the formulation of the control design that aims to make the output of the plant an optimized one. The reference signals are generally pure sine waves of $50 \mathrm{~Hz}$ without any harmonic distortions.

Although various control strategies have been proposed for UPQC with some success, such as PI/PID, hysteresis control, pole shifting and LQR/LQG, these methods are not well efficient in minimizing total harmonic distortion. This study proposes to implement SVPWM with Genetic Algorithm.

\subsection{Genetic Algorithm}

The proposed optimization algorithm belongs to the larger class of Evolutionary Algorithm (EA), which generates solutions to optimization problems using techniques inspired by natural evolution, such as chromosome generation, fitness function, mutation, selection and cross over (Syswerda, 1991). These evaluation processes are performed in the following section.

\section{Step 1: Generation of Chromosome}

The first step of GA is generation of chromosome for the optimization problem. Here, 'N' numbers of random chromosome are generated. The generated chromosomes are considered as the initial chromosome, which is represented as:

$$
\begin{aligned}
& \mathrm{Yi}=\left[\mathrm{y}_{\mathrm{o}}{ }^{(\mathrm{i})} \mathrm{y}_{1}^{(\mathrm{i})} \ldots \mathrm{y}_{\mathrm{NL}-1}\right] ; 0 \leq \mathrm{i} \leq \mathrm{N}_{\mathrm{p}}-1, \\
& 0 \leq \mathrm{j} \leq \mathrm{N}_{\mathrm{L}}-1
\end{aligned}
$$

\section{Where:}

$y_{j}{ }^{(i)}=$ The $j^{\text {th }}$ gene of the chromosome
$N_{p}=$ The population pool
$N_{L}=$ The length of the chromosome 


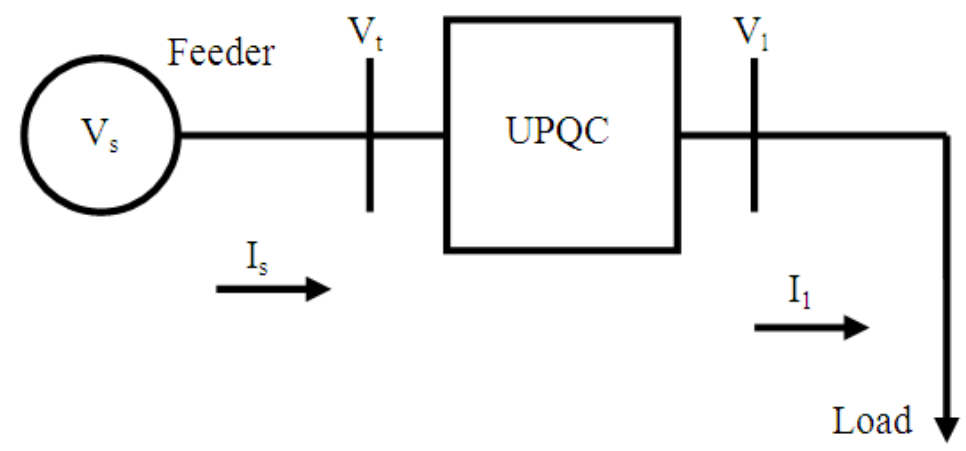

Fig. 1. Schematic diagram of a UPQC compensated system

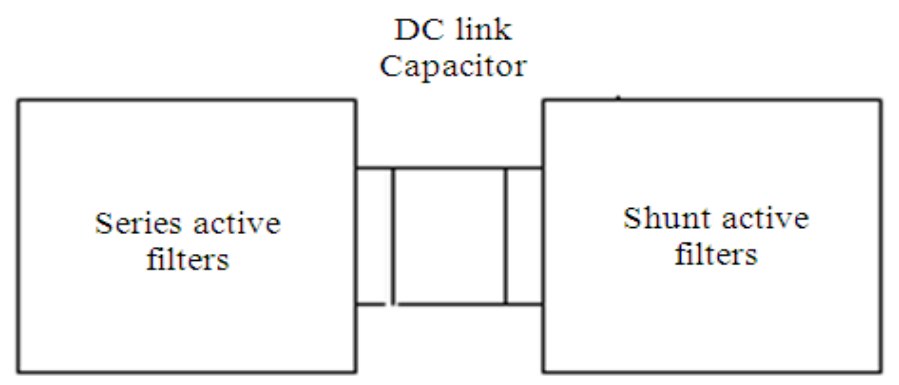

Fig. 2. Filters with DC link capacitor

Here, the error Voltage (Ve) and change of error Voltage $(\mathrm{V} \Delta \mathrm{e})$ are the target parameters of dc-link regulated Voltage (VDC). If the chromosome length $\mathrm{NL}=2$, then the error voltage is chosen between the minimum and maximum values i.e., yo(i) $€[$ Ve min, Ve max] and y1(i) $€$ $[\mathrm{V} \Delta \mathrm{e} \min , \mathrm{V} \Delta \mathrm{e} \max ]$. From the error value, the respective optimized dc-link voltage is selected. This generation process is also called as initialization process. After generating chromosome, the next step is to calculate the fitness value for the generated chromosome.

\section{Step 2: Fitness Function}

Fitness function is one of the types of objective function, which is the leading target parameter to the optimized value. Here, the fitness function is used to determine the regulated dc-link voltage. The dc-link voltage (VDC) is achieved by determining the capacitor current (Ic). The fitness function is calculated by using the following formula:

Fitness function, $\mathrm{Ic}=\mathrm{C} \mathrm{d} / \mathrm{dt}(\mathrm{Ve}, \mathrm{V} \Delta \mathrm{e})$

Using the equation, the Ic is calculated by the respective error and change of error voltage. From this value, the dc-link voltage is determined.

The crossover operation is performed between two chromosomes to obtain a new chromosome. The crossover operation is done based on the crossover rate Cr. Based on this crossover rate, the genes are selected and a new child chromosome is generated, After generating new chromosome, a fitness function is applied to the new child chromosome. The formula for calculating the cross over rate is described as follows:

$$
\text { Crossover rate } C^{r}=\frac{\text { No : of gene cross over }}{\text { Chromosome Length }}
$$

\section{Step 3: Mutation Operation}

The mutation operation is done based on the Mutation rate $(\mathrm{Mr})$. The formula for calculating the mutation rate is given below:

$$
\text { Mutation rate }\left(\mathrm{M}_{\mathrm{r}}\right)=\mathrm{Mp} / \mathrm{N}_{\mathrm{L}}
$$

Where:

$\mathrm{Mp}=$ The mutation point,

$\mathrm{N}_{\mathrm{L}}=$ The chromosome length

\section{Step 4: Termination}

In the termination stage, best chromosome is selected based on the fitness function. The above process is repeated until it reaches the maximum number of iterations. After the completion of termination process a 
possible set of error voltage. Change of error voltage and the corresponding dc-link regulated voltage are obtained, which is described below:

$$
\left(\begin{array}{c}
\left(\mathrm{Ve}^{(1)}, \mathrm{V}_{\Delta} \mathrm{e}^{(1)}\right) \\
\left(\mathrm{Ve}^{(2)}, \mathrm{V}_{\Delta} \mathrm{e}^{(2)}\right) \\
\cdot \\
\cdot \\
\left(\mathrm{Ve}^{(\mathrm{N})}, \mathrm{V}_{\Delta} \mathrm{e}^{(\mathrm{N})}\right)
\end{array}\right)=\left(\begin{array}{c}
\mathrm{VDC}^{(1)} \\
\mathrm{VDC}^{(2)} \\
\\
\mathrm{VDC}^{(\mathrm{N})}
\end{array}\right)
$$

By using the above optimized set of values, the SVPWM system is designed.

\subsection{Space Vector Pulse Width Modulation Technique}

The PWM is controlled by Space Vector modulation. These algorithms are inherited by rapid switching which minimizes the THD (Massoud and Williams, 2010). It creates Alternating Current (AC) waveforms, to drive three phase AC powered motors at varying speeds. Various Space Vector Modulations (SVMs) are accessible that result is different quality and computations required.

\subsection{Principal of SVPWM}

From a combination of switching patterns SVPWM technique approximates the reference voltage.

The sinusoidal voltage is treated as a constant amplitude vector rotating at constant frequency. The transformation is done between ( $a b c$ reference frames to stationary dq frames) in coordinate manner. As shown in Fig. 3 there are six active vectors $\left(\mathrm{V}_{1}\right.$ to $\left.\mathrm{V}_{6}\right)$ and two zero vectors $\left(\mathrm{V}_{0}, \mathrm{~V}_{7}\right)$. The six active vectors are rotating around the axes of hexagonal. The load is supplied by the dc link voltage and each sector is $60^{\circ}$ apart. The two zero vectors are at the origin and hence no voltage is supplied to the load.

The overall system block diagram of a three-phase representation of the SVPWM-controlled UPQC, with Genetic Algorithm, is shown in Fig. 4. The Genetic Algorithm renders an optimized set of values by using techniques inspired by natural evolution. Based on these values the SVPWM system is designed. In this way, the procession of THD due to non linear loads is minimized. Thus, the $v_{L}$ and $i_{S}$ will be regulated to suit a pure sine wave and almost a unity power factor will also be achieved at supply side.

\subsection{Simulation studies}

The control studies making up of the SVPWM technique and genetic algorithm described in the previous sections are implemented together as shown in Fig. 5 and their performances are verified through simulation studies in Matlab.

For the investigation purpose a three phase distribution system with some non linear load that which include RL load supplied by a distorted supply voltage is used. The simulation studies are carried over such a load. Different test cases are executed to verify the performance of the UPQC under different supply and load conditions.

Test Case 1-Harmonics compensation at the load current.

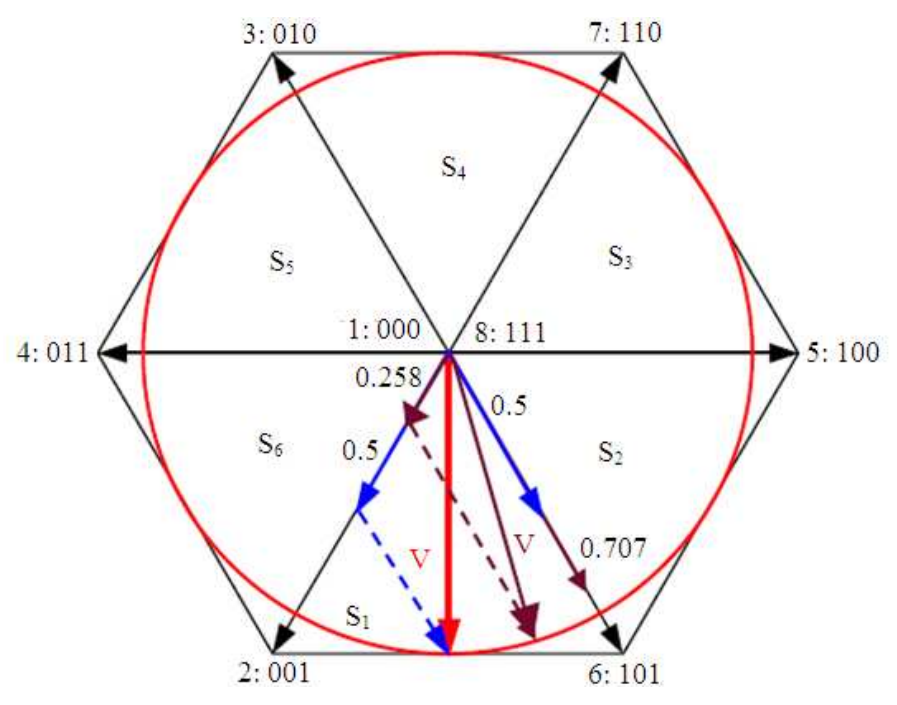

Fig. 3. Switching vectors 
M. Shankar et al. / American Journal of Applied Sciences 11 (1): 152-159, 2014

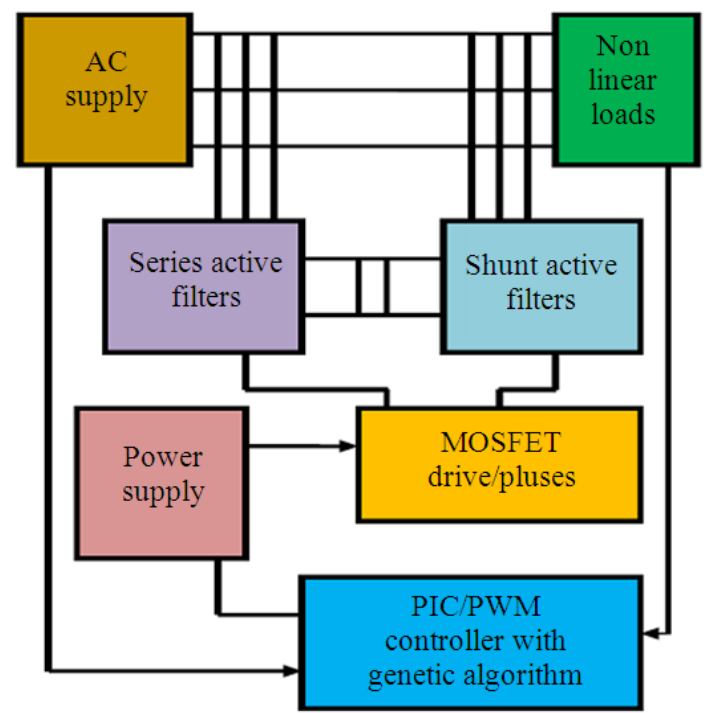

Fig. 4. Block diagram of genetic algorithm based unified power quality conditioner

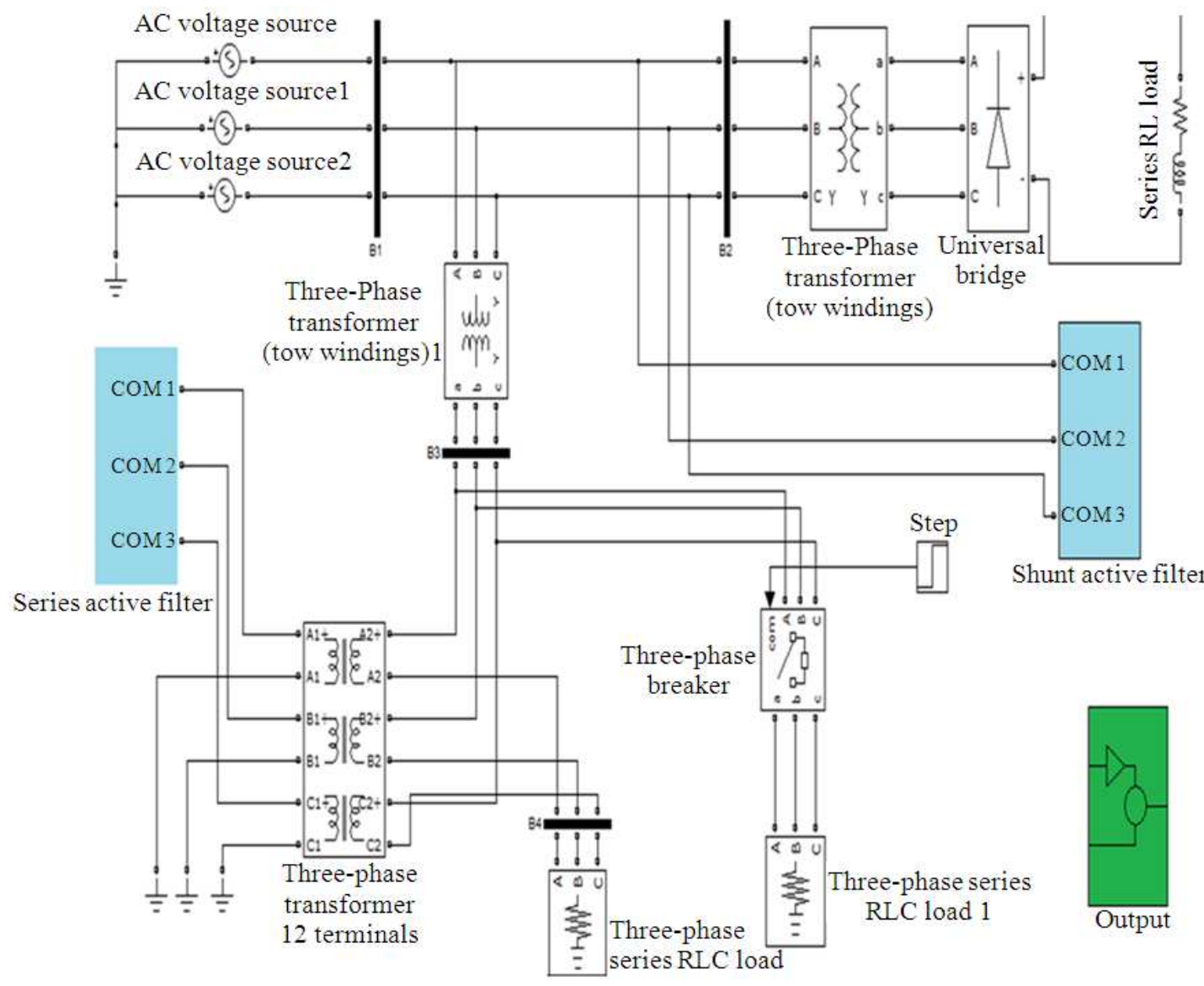

Fig. 5. Simulation diagram 
M. Shankar et al. / American Journal of Applied Sciences 11 (1): 152-159, 2014

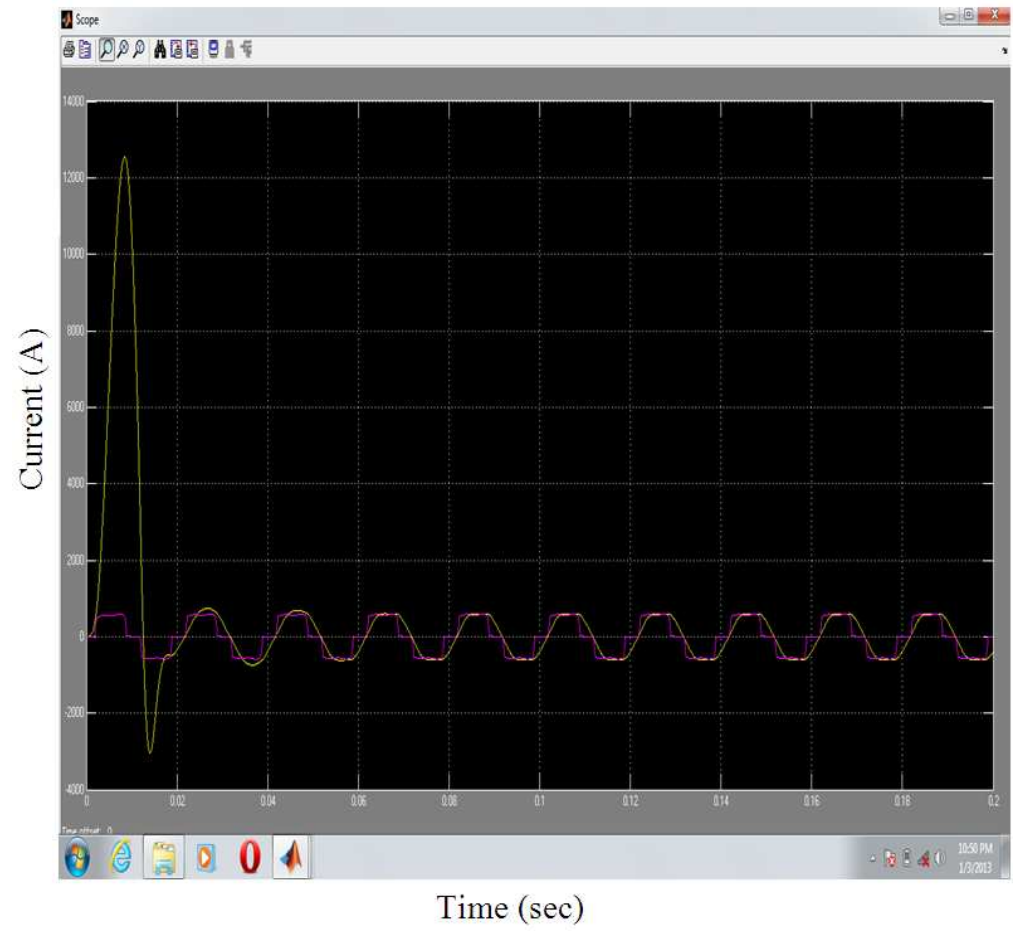

Fig. 6. Current waveforms under distorted supply voltage

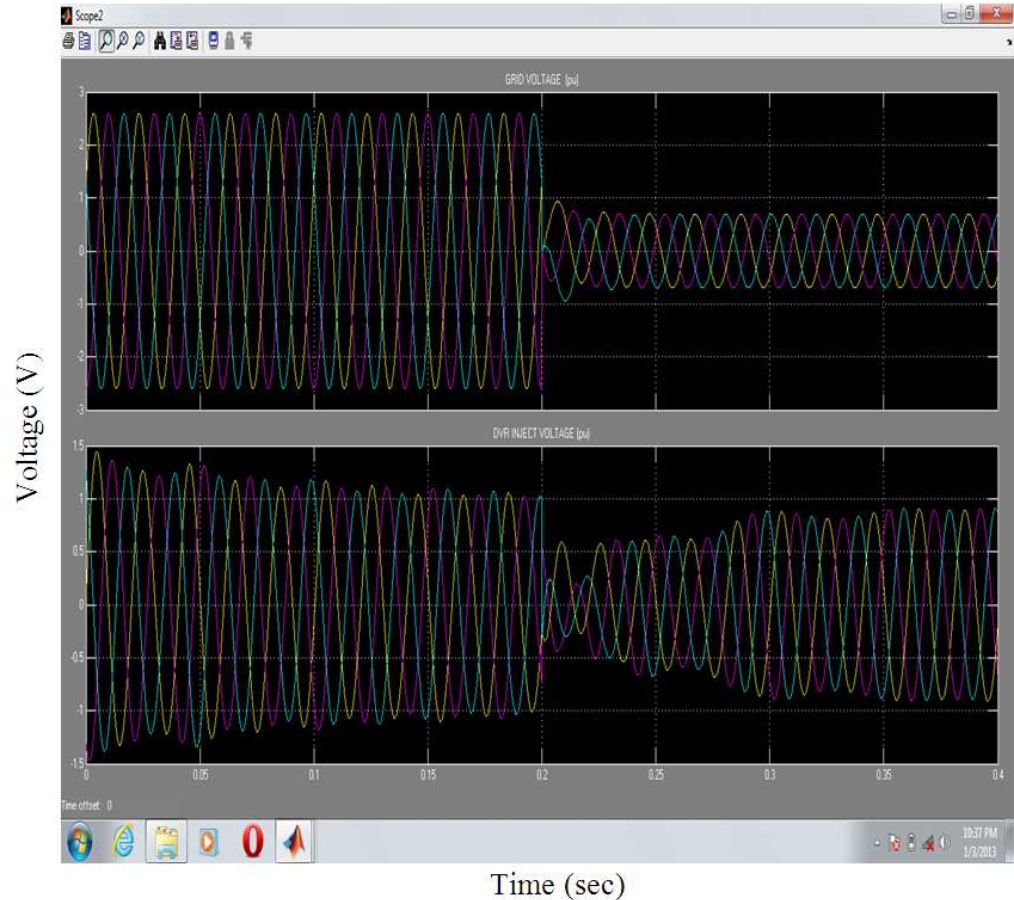

Fig. 7. Voltage and current waveforms under sag and swell conditions 


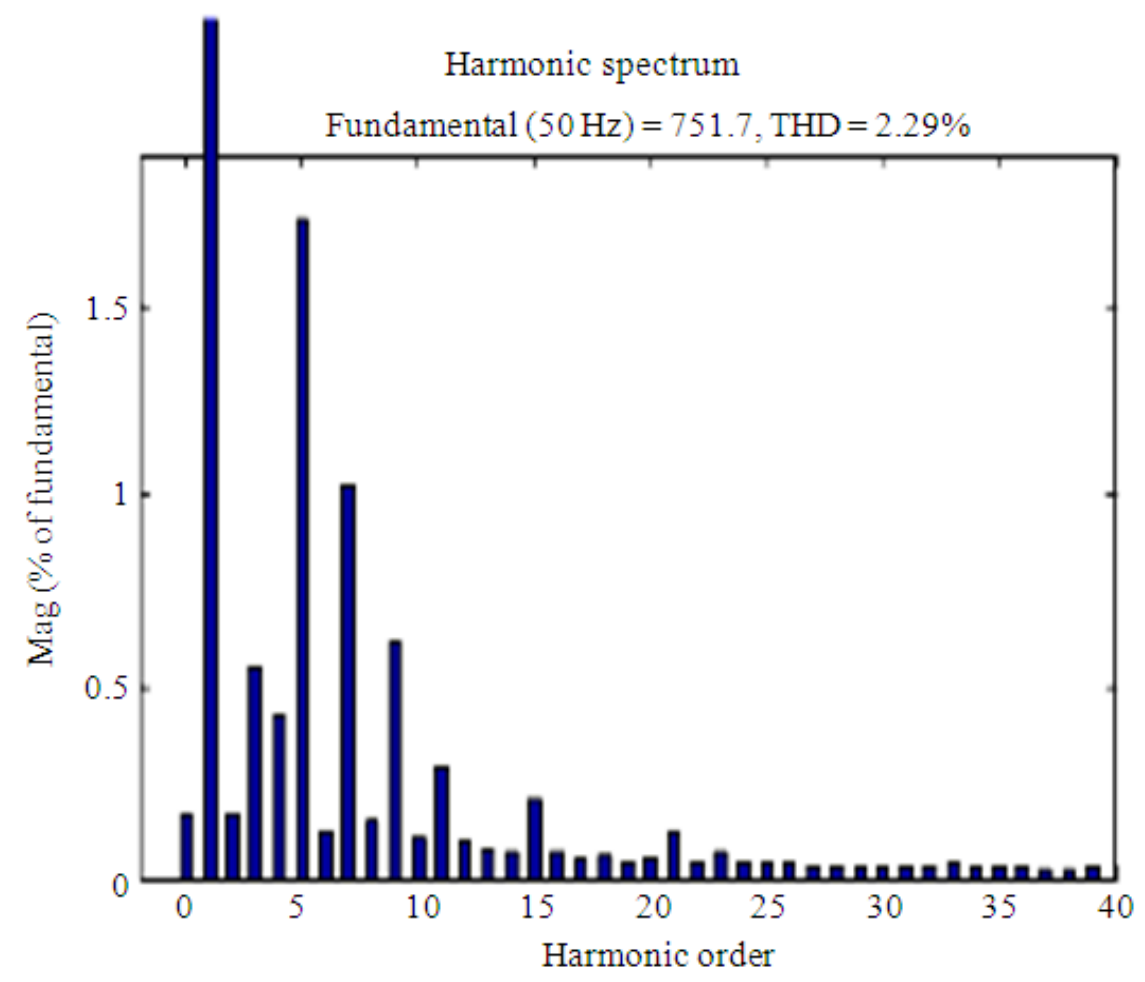

Fig. 8. Total harmonic distortion analysis

The harmonics at the load current is compensated by the UPQC to achieve a near unity power factor at the supply side. This test is performed to verify such capabilities of UPQC. A distorted supply voltage $\mathrm{v}_{\mathrm{S}}$ is used to supply the non linear load with a non linear current $i_{L}$ shown in Fig. 6. $i_{L}$ is also distorted with a lagging power factor and hence with the installation of the UPQC the waveforms of $\mathrm{v}_{\mathrm{L}}$ and is are near sinusoidal as the UPQC is initialized. This is achieved at a period of less than two cycles.

Test Case 2-Disturbances in the Supply voltage: To ensure the amplitude of load voltage remains unchanged the UPQC compensates sag/swell in the supply voltage and in addition it compensates harmonics. In Fig. 7 the voltage waveforms under different operational conditions of supply voltage in the system is shown. For $0.15 \leq \mathrm{t}<0.2 \mathrm{~s}$, the swell is cleared and for $0.35 \leq \mathrm{t}<0.4 \mathrm{~s}$ the sag is cleared.

The harmonics that originates as currents has a prominent effect on the power quality. The measurement of the harmonic distortions present in the signal is referred as THD. In this study with the implementation of genetic algorithm and SVPWM control algorithm the THD is minimized up to $2.29 \%$ for a signal of frequency 50 hertz as shown in Fig. 8.

\section{CONCLUSION}

The control design that optimizes the output of the plant is discussed. This control design consists of Genetic Algorithm based SVPWM technique. Genetic Algorithm determines optimum points and angle for filtering and Space Vector Pulse Width Modulation Technique (SVPWM) offer significant flexibility to optimize waveform. The larger class of Evolutionary Algorithm (EA), is the Genetic Algorithm which optimizes the output by generating solutions to optimization generation, fitness function, mutation, selection and crossover. These techniques are inspired by natural evolution. The line charging circuit can also be used with UPQC to make the system more effective by operating independently. Further the 12-IGBT configuration with two capacitors grounded at the midpoint can be selected.

\section{REFERENCES}

Barros, J.D. and J.F. Silva, 2010. Multilevel optimal predictive dynamic voltage restorer. IEEE Trans. Indus. Electron., 57: 2747-2760. DOI: 10.1109/TIE.2009.2034172 
Chen, Z. and M. Chen, 2012. Control and performance of a cascaded shunt active power filter for aircraft electric power system. IEEE Trans. Indus. Electron., 59: 3614-3624. DOI: 10.1109/TIE.2011.2166231

Fujita, H. and H. Akagi, 1998. The unified power quality conditioner: The integration of series-and shuntactive filters. IEEE Trans. Power Electron, 13: 315322. DOI: $10.1109 / 63.662847$

Khadkikar, V. and A. Chandra, 2009. A novel structure for three-phase four-wire distribution system utilizing Unified Power Quality Conditioner (UPQC). IEEE Trans. Indus. Applic., 45: 18971902. DOI: $10.1109 /$ TIA.2009.2027147

Kim, D.E. and D.C. Lee, 2010. Feedback linearization control of three-phase UPS inverter systems. IEEE Trans. Indus. Electron., 57: 963-968. DOI: 10.1109/TIE.2009.2038404

Kolhatkar, Y. and S.P. Das, 2007. Experimental investigation of a single-phase UPQC with minimum VA loading. IEEE Trans. Power Del., 22: 373-380. DOI: 10.1109/TPWRD.2006.881471

Kumar, G.S. and M.K. Mishra, 2011. Mitigation of voltage sags with phase jumps by UPQC with PSObased ANFIS. IEEE Trans. Power Del., 26: 27612773. DOI: 10.1109/TPWRD.2011.2165301
Kwan, K.H. and P.L. So, 2009. Model-based Hœ control of a unified power quality conditioner. IEEE Trans. Indus. Electron., 56: 2493-2504. DOI: 10.1109/TIE.2009.2020705

Massoud, A.M. and B.W. Williams, 2010. Evaluation of a multilevel cascaded-type dynamic voltage restorer employing discontinuous space vector modulation. IEEE Trans. Indus. Electron., 57: 2398-2410. DOI: 10.1109/TIE.2010.2041732

Munoz, J.A. J.R. Espinoza, C.R. Baier, L.L. Morán and E.E. Espinosa et al., 2012. Design of a discrete-time linear control strategy for a multicell UPQC. IEEE Trans. Indus. Electron., 59: 3797-3807. DOI: 10.1109/TIE.2011.2160511

Rahmani, S. and K. Al-Haddad, 2012. A lyapunovfunction-based control for a three-phase shunt hybrid active filter. IEEE Trans. Indus. Electron., 59: 1418-1429. DOI: 10.1109/TIE.2011.2163370

Syswerda, G., 1991. Schedule Optimization Using Genetic Algorithm. In: Hand Book of Genetic Algorithm, Davis, L. (Ed.), Van Nostrand Reinhold, New York, USA., pp: 332-349.

Varma, N.R. and K. Neelima, 2012. Control scheme for a UPQC with Integration of series-and shunt-active filters. IJMER, 268-272. 